\title{
Correction to: Proposed Definition for Oligometastatic Recurrence in Biliary Tract Cancer Based on Results of Locoregional Treatment: A Propensity-Score-Stratified Analysis
}

\author{
Koshiro Morino, MD ${ }^{1}$, Satoru Seo, MD, PhD ${ }^{1}$, Tomoaki Yoh, MD, $\mathbf{P h D}^{1}$, Ken Fukumitsu, MD, $\mathbf{P h D}^{1}$, \\ Takamichi Ishii, MD, $\mathrm{PhD}^{1}$, Kojiro Taura, $\mathrm{MD}$, $\mathrm{PhD}^{1}$, Satoshi Morita, $\mathrm{PhD}^{2}$, Toshimi Kaido, $\mathrm{MD}$, PhD, and \\ Shinji Uemoto, MD, PhD \\ ${ }^{1}$ Department of Surgery, Graduate School of Medicine, Kyoto University, Kyoto, Japan; ${ }^{2}$ Department of Biomedical \\ Statistics and Bioinformatics, Graduate School of Medicine, Kyoto University, Kyoto, Japan
}

\section{Correction to: Ann Surg Oncol (2020) 27:1908-1917 https://doi.org/10.1245/s10434-020-08207-0}

In the original article, the calculation (Fig. 3 and Supplementary Table 2) and the following formula of propensity score have errors, and "X1-, X2+, X3+" group should be added into the patients who achieved significantly better SAR from LT; however, only one patient received LT in the group and died 3 months after LT. Based on the clinical course, our finding deviates from the concept that the group that can be expected to prolong survival outcome by LT, and this group was excluded from the definition of "oligometastatic recurrence" (Fig. 4a; before exclusion, Fig. 4b; after exclusion).

Propensity score $=\frac{1}{1+\exp \left(1.427-0.913 X_{1}-0.786 X_{2}-0.416 X_{3}\right)}$

Figures 3 and 4, Table 1, and supplementary Table 2 have been corrected in the original article.

Publisher's NoteSpringer Nature remains neutral with regard to jurisdictional claims in published maps and institutional affiliations.
The original article can be found online at https://doi.org/10.1245/ s10434-020-08207-0.

(C) Society of Surgical Oncology 2021

Published Online: 21 June 2021

S. Seo, $\mathrm{MD}, \mathrm{PhD}$

e-mail: rutosa@kuhp.kyoto-u.ac.jp 